\title{
¡Beccaria está preso en la Cárcel Distrital! Un estudio de caso sobre el "estado de cosas inconstitucional" en las cárceles
}

\section{Beccaria Prisoner in Jail This District! A Case Study on "Unconstitutional State of Affairs" in Prisons}

Fecha de recepción: 15 de octubre de 2010 Fecha de aprobación: 18 de noviembre de 2010

\author{
Luis Alfonso Fajardo Sánchez \\ Heyder Alfonso Camelo"
}

El fin de las penas no es atormentar y afligir a un ente sensible, ni deshacer un delito ya cometido. Tratado de los delitos y las penas Beccaria

\section{Resumen}

El sistema carcelario, como espacio de castigo y cumplimiento de penas por delitos cometidos, es el escenario en el cual el poder del Estado se ejerce de manera visible y con legitimidad plena en sus acciones. Este hecho configura una amenaza constante a la protección y disfrute de los derechos de las personas allí recluidas, las cuales son leídas como ciudadanos de segunda clase, donde todas sus penas y sufrimientos son "justos" como resultado de sus acciones en contra del orden social establecido.

Doctor en derecho de la Universidad Carlos III de Madrid. Coordinador de la línea Derecho y Sociedad de la facultad de Derecho de la Universidad Santo Tomás. Director de la Maestría en defensa de los DD.HH. y del D.I.H. ante organismos, cortes y tribunales internacionales. Correo electrónico: luisfajardo@usantotomas.edu.co

** Sociólogo de la Universidad Santo Tomás, profesor Universitario y consultor. Candidato a Magíster en Derechos Humanos y Litigio ante Cortes Internacinales. USTA. 
La Cárcel Distrital no escapa de estas lógicas, y se configura en una institución totalitaria, donde los derechos humanos de las personas recluidas quedan virtualmente suspendidos mientras cumplen sus penas. Este documento pretende llamar la atención sobre quienes allí se encuentran, mostrando una radiografía de su realidad y cómo a pesar de existir una serie de instrumentos internacionales encaminada a la protección de sus derechos, fallos de estados de cosas inconstitucional por parte de la Honorable Corte Constitucional, las condiciones de los internos e internas no hacen parte de la agenda pública y política del país.

Palabras clave: sistema penitenciario, derechos humanos, castigo, redención.

\begin{abstract}
The prison system as an area of punishment and enforcement of penalties for crimes committed, is the scenario in which state power is exercised in a visible matter and with full legitimacy in their actions. This act constitutes a constant threat to the protection and enjoyment of the rights of the inmates, which are read as second class citizens, where all their pain and suffering is "fair" as a result of their actions against the established social order.

District Jail does not escape this logic, and is set in a totalitarian institution as where human rights of inmates are virtually suspended while serving their sentences. This paper aims to draw attention to those who are there, showing a snapshot of their reality and how, despite a number of international instruments aimed at protecting their rights, unconstitutional failure of states by the Constitutional Court, the conditions for male and female inmates are not part of the public and political agenda of the country.
\end{abstract}

Key words: prison system, human rights, punishment, redemption.

\section{INTRODUCCIÓN}

En toda sociedad, las leyes se reconocen como aquellos lineamientos de comportamiento $y$ normalización de sus miembros, encaminadas a preservar un orden dominante y la convivencia regulada con base en unos mínimos aceptados por la mayoría. Este postulado es quizá de aplicación global, al igual que los mecanismos de sanción para aquellos transgresores de lo pactado. Estos mecanismos, si bien es cierto, varían conforme al contexto cultural, social y político en el cual son desarrollados, pretenden en lo formal un fin común, el de castigar al infractor y enviar un mensaje de visibilización y efectividad en la aplicación de dicho castigo al conjunto de la sociedad, encaminado a generar un efecto disuasivo que prevenga posibles violaciones a la ley (Foucault, 2001, p. 86).
Estos mecanismos son llevados a la práctica a través de distintos métodos y recurren a herramientas disímiles para obtener su cometido; la cárcel como institución hace parte de ellos, al tener como finalidad no sólo el aislamiento de aquellos infractores, sino en especial, la resocialización del individuo a través de estrategias de educación y trabajo que brinden herramientas para su reincorporación al seno de la sociedad. Es en ella donde las personas que han cometido actos contrarios a la ley $y$ que han sido juzgados por personas competentes para tal propósito, cumplen la pena estipulada, esperando que a su término sean sujetos aptos de regresar al sistema social al que pertenecen y llevar una vida "normal" (Foucault, 2000, p. 226).

El desarrollo de los derechos humanos a través de organismos internacionales y de instrumentos 
dirigidos a su protección, ha encaminado esfuerzos frente a la condición de aquellas personas que cumplen una pena como resultado de su transgresión a la ley. La relevancia de estos logros consiste en el reconocimiento de la humanidad plena de aquellos que se encuentran recluidos en las cárceles, pues si bien han cometido una falta y la pena es justa en su proporción, no implica la pérdida de derechos que corresponden a su dignidad y honra de ellos. Es así que el Comité de Derechos Humanos de Naciones Unidas estipula en relación a las personas privadas de la libertad, el goce efectivo de todos los derechos consagrados en los instrumentos internacionales de derechos humanos, sin perjuicio de las restricciones propias derivadas de su condición, debiendo garantizarse el respeto de su dignidad e integridad personal en las mismas condiciones aplicables a las personas que se encuentran en libertad.

En Colombia recientes informes señalan con insistencia que la situación de las personas privadas de la libertad -PPL, es verdaderamente dramática por no decir infame. Los principios pregonados por Cessare Beccaria, para la humanización del derecho penal y de la misma pena, parece que aún no han encontrado plena vigencia en las instituciones penitenciarias del país. Es más, algunos estudios señalan, que aun por el contrario, estos principios son desechados al igual que los convenios y tratados internacionales sobre el particular o desacatadas, como las extraordinarias sentencias de la Corte Constitucional colombiana. Parece ser que los principios de humanidad proclamados entre otros por Beccaria están presos en las cárceles del país y en especial en la Cárcel Distrital de Bogotá.

La Cárcel Distrital como estudio de caso permite un análisis de las condiciones carcelarias que en derechos humanos se están presentando en el país. Al ser considerado por largo tiempo como el mejor centro carcelario del país y uno de los primeros en latinoamericana, es de importancia observar los avances y deficiencias que se observaron, para que sea un ejemplo de administración y respeto de las condiciones de vida de los internos.

La construcción del panorama actual de la cárcel se realiza desde la percepción de los distintos actores que allí convergen, principalmente de la imagen que las personas privadas de la libertad tienen de su día a día, sumada a la respuesta del personal administrativo. Esto es fundamentado mediante informes de gestión y manejo de los registros de la cárcel, para generar un concepto que sea fiel a las dinámicas propias que allí se entablan diariamente y realizar una serie de recomendaciones que permitan la efectiva protección y disfrute de los derechos de las personas que allí se encuentran, reconociendo su vulnerabilidad por sus propias limitaciones en cuanto al derecho a la libertad, y proponiendo estrategias enmarcadas en la búsqueda de garantías reales para los internos sin dilaciones ni penas accesorias por responsabilidades institucionales.

\section{PERSONAS PRIVADAS DE LA LIBERTAD: PREOCUPACIÓN INTERNACIONAL}

La comunidad internacional y los organismos de derechos humanos han recorrido un arduo camino en su propósito por asegurar la protección y el disfrute de los derechos de las personas privadas de la libertad a pesar de su condición de reclusión. Por tal razón, la Asamblea General de Naciones Unidas adopta a través de la Resolución 43/173 de 9 de diciembre de 1988 un conjunto de principios dirigidos a la protección de todas las personas sometidas a cualquier forma de detención o prisión; en ellos se estipula como primer principio la necesidad de que "toda persona sometida a cualquier forma de detención o prisión será tratada humanamente y con el respeto debido a la dignidad inherente al ser humano"; además, su tercer principio señala que no se restringirá o menoscabará ninguno de los derechos humanos de las personas sometidas a 
cualquier forma de detención o prisión reconocidos o vigentes en un Estado en virtud de leyes, convenciones, reglamentos o costumbres "so pretexto de que el presente conjunto de principios no reconoce esos derechos o los reconoce en menor grado".

De igual forma la misma asamblea adopta los principios básicos para el tratamiento de los reclusos, donde se declara:

Todos los reclusos serán tratados con el respeto que merecen su dignidad y valor inherentes de seres humanos.

El personal encargado de las cárceles cumplirá con sus obligaciones en cuanto a la custodia de los reclusos y la protección de la sociedad contra el delito de conformidad con los demás objetivos sociales del Estado y con su responsabilidad fundamental de promover el bienestar y el desarrollo de todos los miembros de la sociedad.

Con excepción de las limitaciones que sean evidentemente necesarias por el hecho del encarcelamiento, todos los reclusos seguirán gozando de los derechos humanos y las libertades fundamentales consagrados en la Declaración Universal de Derechos Humanos y, cuando el Estado de que se trate sea parte, en el Pacto Internacional de Derechos Económicos, Sociales y Culturales y el Pacto Internacional de Derechos Civiles y Políticos y su Protocolo Facultativo, así como de los demás derechos estipulados en otros instrumentos de las Naciones Unidas.

Se crearán condiciones que permitan a los reclusos realizar actividades I aborales remuneradas y útiles que faciliten su reinserción en el mercado laboral del país y les permitan contribuir al sustento económico de su familia y al suyo propio.

Los reclusos tendrán acceso a los servicios de salud de que disponga el país, sin discriminación por su condición jurídica (Resolución 41/111 de diciembre de 1990).

La Asamblea General de Naciones Unidas, preocupada por la situación y el trato de las personas pri- vadas de la libertad, adoptó en el Primer Congreso sobre Prevención del Delito y Tratamiento del Delincuente, las Reglas Mínimas para el Tratamiento de los Reclusos ${ }^{3}$, donde se declara:

Se exigirá del recluso aseo personal y a tal efecto dispondrán de agua y de los artículos de aseo indispensables para su salud y limpieza.

Todo establecimiento penitenciario dispondrá por lo menos de los servicios de un médico calificado que deberá poseer algunos conocimientos psiquiátricos. 1) Los servicios médicos deberán organizarse íntimamente vinculados con la administración general del servicio sanitario de la comunidad o de la nación. Deberán comprender un servicio psiquiátrico para el diagnóstico y, si fuere necesario, para el tratamiento de los casos de enfermedades mentales. 2) Se dispondrá el traslado de los enfermos cuyo estado requiera cuidados especiales, a establecimientos penitenciarios especializados o a hospitales civiles. Cuando el establecimiento disponga de servicios internos de hospital, estos estarán provistos del material, del instrumental y de los productos farmacéuticos necesario para proporcionar a los reclusos enfermos los cuidados y el tratamiento adecuados. Además, el personal deberá poseer su ficiente preparación profesional. 3) Todo recluso debe poder utilizar los servicios de un dentista calificado.

A lo largo de los años los Estados del contiente, en ejercicio de su soberanía, han adoptado una serie de instrumentos internacionales que se han convertido en la base de un sistema regional de promoción y protección de los derechos humanos. Dicho sistema normativo reconoce $y$ define estos derechos, establece obligaciones tendientes a su promoción, protección y a crear órganos destinados a velar por su observancia (Corte Interamericana de Derechos, 2010, p. 4) ${ }^{4}$. En este sentido, la

3 Celebrado en Ginebra en 1955, y aprobadas por el Consejo Económico y Social en sus resoluciones 663C (XXIV) de 31 de julio de 1957 y 2076 (LXII) de 13 de mayo de 1977.

4 Corte Interamericana de Derechos Humanos. Documentos básicos en materia de derechos humanos en el Sistema Interamericano. 
Convención Americana sobre Derechos Humanos (Pacto de San José), estructura un marco de protección donde reconoce:

Toda persona tiene derecho a que se respete su vida. Este derecho estará protegido por la ley y, en general, a partir del momento de la concepción. Nadie puede ser privado de la vida arbitrariamente.

Toda persona tiene derecho a ser oída, con las debidas garantías y dentro de un plazo razonable, por un juez o tribunal competente, independiente e imparcial, establecido con anterioridad por la ley, en la sustanciación de cualquier acusación penal formulada contra ella, o para la determinación de sus derechos y obligaciones de orden civil, laboral, fiscal o de cualquier otro carácter.

Toda persona tiene derecho a un recurso sencillo y rápido o a cualquier otro recurso efectivo ante los jueces o tribunales competentes, que la ampare contra actos que violen sus derechos fundamentales reconocidos por la Constitución, la ley o la presente Convención, aun cuando tal violación sea cometida por personas que actúen en ejercicio de sus funciones oficiales.

Es de anotar, que con base a las Reglas de Brasilia sobre acceso a la justicia de las personas en condición de vulnerabilidad, aprobada en 2008 en la XIV Cumbre Judicial Iberoamericana, se entiende a las personas privadas de la libertad como población vulnerable a la cual debe ser garantizado el acceso a la justicia sin discriminación alguna, englobando el conjunto de políticas, medidas, facilidades y apoyos que permitan a dichas personas el pleno goce de los servicios del sistema judicial, estipulando:

La privación de la libertad, ordenada por autoridad pública competente, puede generar dificultades para ejercitar con plenitud ante el sistema de justicia el resto de derechos de los que es titular la persona privada de libertad, especial- mente cuando concurre alguna causa de vulnerabilidad enumerada en los apartados anteriores (Reglas de Brasilia sobre acceso a la justicia de las personas en condición de vulnerabilidad, aprobada en 2008 en la XIV Cumbre Judicial Iberoamericana, sección 1, numeral 10).

Y con relación a los procesos y trámites que estos deben llevar a cabo sostiene:

Se recomienda la elaboración, aprobación, implementación y fortalecimiento de políticas públicas que garanticen el acceso a la justicia de las personas en condición de vulnerabilidad. Los servidores y operadores del sistema de justicia otorgarán a las personas en condición de vulnerabilidad un trato adecuado a sus circunstancias singulares.

Se adoptarán las medidas necesarias para evitar retrasos en la tramitación de las causas, garantizando la pronta resolución judicial, así como una ejecución rápida de lo resuelto. Cuando las circunstancias de la situación de vulnerabilidad lo aconsejen, se otorgará prioridad en la atención, resolución y ejecución del caso por parte de los órganos del sistema de justicia.

Se velará para que la comparecencia en actos judiciales de una persona en condición de vulnerabilidad se realice de manera adecuada a las circunstancias propias de dicha condición (Reglas de Brasilia sobre acceso a la justicia de las personas en condición de vulnerabilidad, aprobada en 2008 en la XIV Cumbre Judicial Iberoamericana, seccion 1, numeral 10).

El marco normativo internacional en temas de derechos humanos es claro en procurar la protección de la integridad y el disfrute de los derechos de las personas privadas de la libertad, enfatizando la responsabilidad por parte del Estado de garantizar las condiciones necesarias para la efectividad de las medidas tomadas en el momento de la detención y la reclusión. En concordancia con este propósito, la Comisión Interamericana de Derechos Humanos adopta los principios y buenas prácticas sobre la protección de las personas privadas de la libertad 
en las Américas, iniciando con el trato humano como primer principio, según el cual:

Toda persona privada de libertad que esté sujeta a la jurisdicción de cualquiera de los Estados Miembros de la Organización de los Estados Americanos será tratada humanamente, con irrestricto respeto a su dignidad inherente, a sus derechos y garantías fundamentales, y con estricto apego a los instrumentos internacionales sobre derechos humanos (OEA/Ser/L/V/ II.131, doc. 26).

Con respecto al derecho a la salud, estos principios señalan:

Las personas privadas de libertad tendrán derecho a la salud, entendida como el disfrute del más alto nivel posible de bienestar físico, mental y social, que incluye, entre otros, la atención médica, psiquiátrica y odontológica adecuada; la disponibilidad permanente de personal médico idóneo e imparcial; el acceso a tratamiento y medicamentos apropiados y gratuitos; la implementación de programas de educación y promoción en salud, inmunización, prevención y tratamiento de enfermedades infecciosas, endémicas y de otra índole; y las medidas especiales para satisfacer las necesidades particulares de salud de las personas privadas de libertad pertenecientes a grupos vulnerables o de alto riesgo, tales como: las personas adultas mayores, las mujeres, los niños y las niñas, las personas con discapacidad, las personas portadoras del VIH-SIDA, tuberculosis, y las personas con enfermedades en fase terminal. El tratamiento deberá basarse en principios científicos y aplicar las mejores prácticas.

Al ser reconocidos como un grupo en condiciones de vulnerabilidad, la Corte Interamericana de Derechos Humanos anota:

Frente a las personas privadas de libertad, el Estado se encuentra en una posición especial de garante, toda vez que las autoridades penitenciarias ejercen un fuerte control o dominio sobre las personas que se encuentran sujetas a su custodia. De este modo, se produce una relación e interacción especial de sujeción entre la persona privada de libertad y el Estado, caracterizada por la particular intensidad con que el Estado puede regular sus derechos y obligaciones y por las circunstancias propias del encierro, en donde al recluso se le impide satisfacer por cuenta propia una serie de necesidades básicas que son esenciales para el desarrollo de una vida digna ${ }^{5}$.

En este mismo sentido, "la misma Corte Interamericana de Derechos Humanos en Sentencia del Caso Fermín Ramírez vs Guatemala" (2005), aclara puntualmente con base en el artículo 5.1 y 5.2 de la Convención Americana sobre Derechos Humanos:

1. Toda persona tiene derecho a que se respete su integridad física, psíquica y moral.

2. Nadie debe ser sometido a torturas ni a penas o tratos crueles, inhumanos o degradantes. Toda persona privada de libertad será tratada con el respeto debido a la dignidad inherente al ser humano.

El caso citado permite a la Corte Interamericana con base en el artículo 5 referente a la integridad personal, plasmar su preocupación e interés constante por las condiciones en las cuales los reclusos cumplen sus condenas, y si estas son adecuadas y coadyuvan en el proceso de reinserción social. En este punto la Corte da especial relevancia a la existencia de servicio médico, dental y psicológico adecuados y responsables, con aras de preservar la integridad de las personas en reclusión. Complementario a estas disposiciones, el artículo 17 referente a la protección a la familia, permite resaltar la importancia que tiene para los internos relacionarse con sus hijos, pues estos espacios dan cumplimiento pleno a la Convención de los Derechos de los Niños y propende por el adecuado proceso de resocialización de las personas.

5 Corte IDH, Caso "Instituto de Reeducación del Menor" Vs. Paraguay, Sentencia de 2 de septiembre de 2004 (Excepciones Preliminares, Fondo, Reparaciones y Costas), párr. 152. 
Lo expuesto hasta aquí denota la importancia que se le ha otorgado al trato y a las condiciones de satisfacción de los derechos de los internos en las instituciones penitenciarias, fijando los instrumentos internacionales para una posición de protección a la condición de seres humanos de los condenados, y la obligación que tiene el Estado a invertir todos los recursos para que estos propósitos y normas se lleven a feliz término. Colombia no puede ser ajena a estas disposiciones internacionales en materia de derechos humanos, por ser signatario de la Convención Interamericana y de los pactos internacionales, se ve exhortada a trabajar en la consecución y garantía de los derechos de las personas privadas de la libertad. Tan es así que la misma Comisión Interamericana de Derechos Humanos para el 2010 “otorgó medidas cautelares a favor de Diomedes Meneses Carvajalino, quien se encuentra recluido en la cárcel de Palo Gordo, Municipio de Girón, Departamento de Santander. En la solicitud de medida cautelar se alega que la vida y la salud del señor Meneses Carvajalino se encuentran en grave peligro debido a que en la prisión donde se encuentra no se le habría provisto atención médica adecuada para atender un problema de salud que padece desde principios de 2009. La Comisión Interamericana solicitó al Estado de Colombia que adopte las medidas necesarias para brindar la atención médica adecuada que permita la protección de la vida, integridad personal y salud del señor Meneses Carvajalino; que concierte las medidas a adoptarse con el beneficiario y/o su representante; y que informe sobre las acciones adoptadas a fin de investigar los hechos que dieron lugar a la adopción de medidas cautelares".

La salud es un tema prioritario en la protección de los derechos de las personas privadas de la libertad, en especial, aquellas que padecen algún tipo de enfermedad terminal. Al respecto es necesario recordar las directrices sobre el VIH/SIDA y los derechos humanos, aprobada en la Segunda
Consulta Internacional celebrada en Ginebra en 1996, donde se afirma:

La pena de privación de libertad no debería provocar la pérdida de los derechos humanos o la dignidad. En particular, el Estado, por medio de las autoridades penitenciarias, tiene el deber de cuidar a los presos, lo que entraña el deber de proteger los derechos a la vida y a la salud de todas las personas privadas de libertad. Negar a los reclusos la posibilidad de recibir información, educación y medios de prevención (desinfectante, preservativos, material de inyección inocua) con respecto al $\mathrm{VIH}$, la prueba voluntaria y el asesoramiento, la confidencialidad y la atención médica en materia de VIH, así como la posibilidad de someterse voluntariamente a tratamientos experimentales, podrían constituir tratos o penas crueles, inhumanos o degradantes. El deber de cuidado entraña asimismo el de combatir la violación y otras formas de victimización sexual en la cárcel, que pueden ocasionar, entre otras cosas, la transmisión del VIH.

El tema es recurrente en los instrumentos internacionales, pues es de vital importancia la protección de los derechos de las personas privadas de la libertad, a no ser discriminadas por ser portadores de una enfermedad terminal y porque los sistemas penitenciarios sean garantes del disfrute pleno de su dignidad. En este sentido, las directrices de la OMS sobre la infección por el VIH y el SIDA en las cárceles publicadas en 1993, anotan, con respecto al trato debido, lo siguiente:

El aislamiento por períodos limitados puede ser necesario por razones médicas para infectados por el VIH que sufren los presos de tuberculosis pulmonar en una fase infecciosa, el aislamiento de protección también puede ser necesario para prisioneros con inmunodepresión relacionados con el SIDA, sino que debe llevarse a cabo sólo con un preso en forma de consentimiento. Las decisiones sobre la necesidad de aislar o segregar a los presos (incluidos los infectados por el VIH) sólo se deben tomar por razones 
médicas y sólo por personal de salud, y no debe ser influido por la administración penitenciaria.

\section{MARCO NORMATIVO COLOMBIANO}

En concordancia con la evolución en el plano internacional en temas de protección, garantía y respeto de los derechos de las personas privadas de la libertad, Colombia ha realizado esfuerzos encaminados en esa dirección. Al ser el Estado signatario de la Convención Interamericana, de los pactos de derechos humanos y de la Declaración de Derechos Humanos, los organismos internacionales fijan sus miradas sobre la situación carcelaria del país. Los procesos de globalización e internacionalización de la justicia, demandan de los países signatarios de estos mecanismos de protección, un trabajo eficiente y eficaz en la mejoría de las condiciones de reclusión de los internos.

Desafortunadamente los esfuerzos del Estado colombiano no han sido los mejores y mucho menos los más eficaces, tan es así, que la Corte Constitucional, en su papel de guardiana de la integridad y supremacía de la Constitución Política, ha producido importante jurisprudencia en este sentido, para que de manera inmediata, las condiciones de los internos mejoren y sus derechos sean respetados.

Para tal efecto, la Corte Constitucional, a través de su Sentencia T-153 de 1998, ha declarado el estado de cosas inconstitucional con relación al hacinamiento que se presenta en las cárceles colombianas, anotando:

Las cáceles colombianas se caracterizan por el hacinamiento, las graves deficiencias en materia de servicios públicos y asistenciales, el imperio de la violencia, la extorsión y la corrupción, y la carencia de oportunidades y medios para la resocialización de los reclusos. Esta situación se ajusta plenamente a la definición del estado de cosas inconstitucional. Y de allí se deduce una flagrante violación de un abanico de derechos fundamentales de los internos en los centros penitenciarios colombianos, tales como la dignidad, la vida e integridad personal, los derechos a la familia, a la salud, al trabajo y a la presunción de inocencia, etc. Durante muchos años, la sociedad y el Estado se han cruzado de brazos frente a esta situación, observando con indiferencia la tragedia diaria de las cárceles, a pesar de que ella representaba día a día la transgresión de la Constitución y de las leyes. Las circunstancias en las que transcurre la vida en las cárceles exigen una pronta solución (Sentencia T-153 de 1998, M.P. Eduardo Cifuentes).

La Corte Constitucional encamina sus decisiones no sólo a la protección eficaz de los derechos de las personas privadas de la libertad desde un enfoque integral, el cual, en palabras de Libardo Herreño implica:

[...] adoptar la idea de integralidad de los derechos humanos, supone, por ende, asumir mediante este principio una visión más global de la realidad humana, que evite miradas parciales o dispersas de los individuos y de los grupos humanos que son titulares de los derechos (Herreño, 2008, p. 33).

En la Sentencia T-153 de 1998, M.P. Eduardo Cifuentes, también plantea la función de los centros carcelarios en las siguientes palabras:
La labor de resocialización no consis- te en imponer determinados valores a los reclusos, sino en brindarles los medios para que, haciendo uso de su autodeterminación, establezca cada interno el camino de su reinserción al conglomerado social. (Sentencia T-153 de 1998, M.P. Eduardo Cifuentes).

En la sentencia citada, al encontrar dicho estado de inconstitucionalidad, afirma con contundencia:

Tanto el derecho a la dignidad como el de no recibir tratos o penas crueles, inhumanos o degradantes se ven quebrantados por el hacinamiento y las malas condiciones de la estructura física y de servicios públicos que se encuentra en los centros de reclusión; los derechos a la vida y la 
integridad física son vulnerados o amenazados de manera inminente por el mismo hacinamiento, por la mixtura de todas las categorías de reclusos y por la carencia de los efectivos de guardia requeridos; el derecho a la familia es quebrantado por la sobrepoblación carcelaria y las deficiencias administrativas, condiciones éstas que implican que los visitantes de los reclusos han de soportar prolongadas esperas, bajo las inclemencias del clima, para poder ingresar al centro, y que dificultan en grado extremo las visitas conyugales y familiares; el derecho a la salud se conculca dadas las carencias infraestructurales de las áreas sanitarias, la congestión carcelaria, la deficiencia de los servicios de agua y alcantarillado y la escasez de guardia para cumplir con las remisiones a los centros hospitalarios; Ios derechos al trabajo y a la educación son violados, como quiera que un altísimo porcentaje de los reclusos no obtiene oportunidades de trabajo o de educación y que el acceso a estos derechos está condicionado por la extorsión y la corrupción; el derecho a la presunción de inocencia se quebranta en la medida en que se mezcla a los sindicados con los condenados y en que no se establecen condiciones especiales, más benévolas, para la reclusión de los primeros, etc. (Sentencia T-153 de 1998, M.P. Eduardo Cifuentes).

Al exponer lo anterior la Corte establece un precedente con respecto a los derechos humanos de las personas privadas de la libertad, pues reconoce que objeto mismo de la inconstitucionalidad lo constituye el hacinamiento padecido por los internos. Dicho fenómeno, vulnera de manera directa derechos tales como el trabajo, la educación, la alimentación, la salud, la familia, la recreación, etc., puesto que:

[...] los puestos de trabajo y de educación son escasos en relación con la demanda sobre ellos, lo cual significa, que en estas áreas se impone la ley del más fuerte y campea la corrupción y la extorsión. Igualmente, es evidente para todos que los procedimientos para las visitas -con las esperas interminables, la falta de espacio para las visitas conyugales y familiares, etc.- no facilitan la unidad e integración familiar". Así mismo, se conocen de muchos casos de personas enfermas que requieren tratamiento hospitalario, pero no pueden ser trasladados a los centros médicos por carencia de personal de guardia. Hechos similares ocurren con las diligencias judiciales, etc. (Sentencia T-153 de 1998, M.P. Eduardo Cifuentes).

Así mismo, la Corte Constitucional, en su Sentencia T-606 de 1998, declaró un estado de cosas inconstitucional con relación a la salud, asistencia médica y suministro de medicamentos a internos, aclarando que el hecho de que las personas privadas de la libertad vean reducidos determinados derechos por esta condición, no significa que el recluso quede indefenso ante el ordenamiento jurídico y menos que se halle imposibilitado, en cuanto persona, para reclamar el respeto al núcleo esencial de la generalidad de sus derechos fundamentales:

[...] habiendo sido prohibida en el sistema colombiano la pena de muerte (art. 11 C.P.) y estando proscrita toda clase de castigos que impliquen tortura, tratos crueles, inhumanos o degradantes (art. 12 C.P.), los derechos a la vida, a la integridad personal y a la salud, en conexión con aquellos, permanecen intactos. Es decir, no pueden resultar afectados ni en mínima parte durante el tiempo necesario para el pago de la pena impuesta o a lo largo del período de detención cautelar.

Por la salud del interno debe velar el sistema carcelario, a costa del tesoro público, y la atención correspondiente incluye, también a su cargo, los aspectos médicos, quirúrgicos, hospitalarios y farmacéuticos, entre otros. Los derechos fundamentales del preso resultarían gravemente violados por la negligencia estatal en estas materias, así como por la falta de cuidado y asistencia requeridos para la prevención, conservación y recuperación de su salud (Sentencia T-606 de 1998, M.P. José Gregorio Hernández).

La Corte Constitucional con estas afirmaciones busca generar un marco de protección eficiente para los derechos de los internos de las cárceles 
del país, donde sea el Estado el que deba asumir su responsabilidad en la garantía al disfrute pleno de estos, al asegurar que:

[...] el conjunto de prestaciones que en el plano del servicio médico deben asumir los establecimientos carcelarios está constituida por la oportuna práctica de los exámenes y pruebas técnicas que permitan establecer o descartar si la persona presenta cierta afección o irregularidad en su estructura corporal o funcional en cualquiera de los múltiples aspectos integrantes del equilibrio orgánico (Sentencia T-606 de 1998, M.P. José Gregorio Hernández).

Y resalta diciendo:

Es notorio que si, a la luz de la Constitución (art. 49), la atención de la salud y el saneamiento ambiental son servicios públicos a cargo del Estado y que, si a todas las personas está garantizado por la Carta el acceso a los servicios de promoción, protección y recuperación de aquélla, conforme a los principios de eficiencia, universalidad y solidaridad, las circunstancias de un importante sector de la población, compuesto por los presos, ameritan que el Estado Social de Derecho aplique con carácter urgente el artículo 13 de la Constitución, que le manda promover las condiciones para que la igualdad sea real y efectiva, adoptar medidas en favor de grupos discriminados o marginados y proteger especialmente a aquellas personas que por su condición económica, física o mental, se encuentren en circunstancia de debilidad manifiesta (Sentencia T-606 de 1998, M.P. José Gregorio Hernández).

Lo expuesto con anterioridad visibiliza los esfuerzos de la Corte Constitucional por restaurar los derechos de las personas privadas de la libertad, los cuales no pueden esperar -en términos de salud- a las acciones reactivas por parte de las instituciones carcelarias, sino que también la omisión en la atención, prevención, control y seguimiento de los tratamientos de los internos, se consolidan como afectaciones directas. El Estado debe asegurar a través de las instituciones encargadas para tal fin, la generación de estrategias preventivas ante los eventuales problemas de salud de los internos, y el control de los tratamientos, posterior a los exámenes necesarios para cada caso. El Estado está obligado por la legislación nacional, y por los instrumentos y la jurisprudencia internacional, de garantizar la protección y generar condiciones de satisfacción plena de los derechos de las personas privadas de la libertad, sin importar su condición de reclusión por razón de las penas a las cuales hayan sido condenados.

Como consecuencia del desarrollo jurisprudencial de la Corte Constitucional, en temas de protección de los derechos humanos de las personas privadas de la libertad, se ha hecho referencia también a las visitas intimas y la libre determinación de su opción sexual, sin discriminación alguna por diferencias en sus preferencias. Sobre el derecho al libre desarrollo de la personalidad, en razón al ejercicio de la sexualidad de las personas privadas de la libertad, ha dicho la Corte:

Una de las facetas en las que se ve plasmado el derecho al libre desarrollo de la personalidad es la sexualidad del ser humano el cual debe verse de una manera integral teniendo en cuenta, por tanto, el aspecto corporal o físico. La relación sexual es una de las principales manifestaciones de la sexualidad. La privación de la libertad conlleva una reducción del campo del libre desarrollo de la personalidad, pero no lo anula.

La relación física entre el recluso y su visitante es uno de los ámbitos del libre desarrollo de la personalidad que continúa protegido aún en prisión, a pesar de las restricciones legítimas conexas a la privación de la libertad (Sentencia T-499 de 2003, M.P. Álvaro Tafur Galvis).

En investigaciones recientes hemos acuñado el concepto del "Efecto Gulliver" para graficar de algún modo el fenómeno relacionado con el incumplimiento a las sentencias de la Corte Constitucional colombiana: 
Una corte gigante en un país de instituciones liliputienses". Las tres extraordinarias sentencias del Estado de Cosas Inconstitucionales que tienen efectos erga omnes que este tribunal constitucional ha fallado sobre la protección y restablecimiento de los derechos de las personas privadas de la libertad en centros penitenciarios, han sido sistemáticamente desacatadas sin ninguna consecuencia para las entidades renuentes. Ningún tema en el país ha sido objeto de más de una sentencia de "Estado de Cosas Inconstitucionales", este tema ha tenido no una sino tres de estas estructurales sentencias. En ningún caso como en el tema de los derechos de la PPL se puede demostrar "el Efecto Gulliver" (Fajardo, 2009).

\section{LA CÁRCEL DISTRITAL DE VARONES Y ANEXO DE MUJERES FRENTE A LA PROTECCIÓN DE LOS DERECHOS DE LAS PPL}

La realidad en Colombia en cuanto al sistema penitenciario es desalentadora en términos de cumplimiento de los pactos y tratados internacionales en materia de derechos humanos, pero en especial, visibiliza un estado de discriminación y de insensibilidad por la condición del otro. Goffman afirma que el problema del otro radica en el nivel de normalidad que damos a las acciones y condiciones de las personas (Goffman, 1998, p. 28); de allí la preocupación o displicencia por las condiciones de las personas privadas de la libertad, al asumir que por las faltas cometidas se puede despojar de su condición de sujetos de derechos y transformarlos en seres de segunda categoría.

La labor que el Distrito ha emprendido en la visibilización y protección de grupos vulnerables, al igual que la construcción de programas y proyectos que permitan la estructura de una ciudad de derechos debe ser valorada. El esfuerzo presupuestal y humano que se ha direccionado en estrategias que permitan garantizar el disfrute pleno de los derechos de personas históricamente discrimina- das, o de grupos en proceso de consolidación y obtención de un status social legitimo, permite, realizar un balance general, observar y realizar avances significativos en lo particular.

\section{DERECHOS DE LAS PERSONAS PRIVADAS DE LA LIBERTAD: PANORAMA ACTUAL}

\section{Derecho a la salud}

La mayor afectación encontrada que vulnera de manera directa los derechos de las personas privadas de la libertad es la ausencia de garantía en cuanto condiciones óptimas que preserven su salud. Esta situación se hace manifiesta por dos hechos que lejos de ser coyunturales, son parte de un sistema inequitativo y violento hacia el interno.

El primer hecho es la intermitencia en el servicio de agua para la cárcel. Al ser una institución que en lo formal tiene la capacidad total de retención de 1028 personas, y con base en testimonios obtenidos por los guardias entrevistados esta cifra puede ser mayor $y$ tendiente a un potencial hacinamiento, el suministro diario de agua potable para el aseo personal y de la institución se hace fundamental. La ausencia de este bien esencial para las personas que se encuentran recluidas, por su misma condición de confinamiento, hacen que su integridad física se vea directamente amenazada por los riesgos que trae la convivencia de un promedio de 190 personas por pabellón, las cuales no se encuentran exentas de enfermedades o problemas de salubridad ${ }^{6}$. Tan grave es el problema encontrado, que en el Pabellón Autonomía, donde se encuentran recluidos 190 internos, se presentó una epidemia gastrointestinal que afectó a la mayoría de ellos, haciendo que se generara una vulneración flagrante a su integridad física y

$6 \quad$ La Resolución 1/08 de la Comisión Interamericana de Derechos Humanos establece: Principio XI. 2. Agua potable. Toda persona privada de libertad tendrá acceso en todo momento a agua potable suficiente y adecuada para su consumo. Su suspensión o limitación, como medida disciplinaria, deberá ser prohibida por la ley. 
al compromiso por parte del Distrito de garantizar el pleno disfrute de los derechos de los internos.

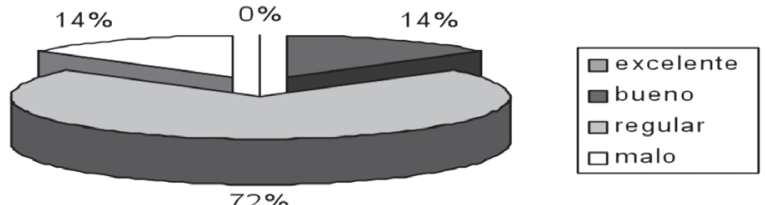

Figura 1. Percepción comité derechos humanos - salud.

Tomando como muestra representativa del Comité de Derechos Humanos ${ }^{7}$, vemos reflejado, en el figura 1, la deteriorada imagen que tiene la prestación de los servicios de salud en la Cárcel. La mayoría de sus miembros expresan su insatisfacción en la manera en que está regulado el tema, pues anotan que si bien es cierto tienen derecho a una consulta mensual al servicio médico y de enfermería, al agotar su "cuota" mensual no pueden volver a recurrir por alguna otra dolencia, a menos que sea una urgencia que amerite ser revisada. En palabras de ellos "una súper urgencia al borde de la muerte", para que se permita ser remitidos a la revisión necesaria. Además, añaden el seguimiento a los procedimientos médicos de aquellos que se encuentran en tratamiento es pobre y descuidado.

Ligado a los problemas expuestos del agua, la segunda situación urgente y que va en detrimento directo -especialmente- de las internas del Pabellón Esperanza, es el servicio de odontología. Este servicio no ha sido prestado a las internas desde

7 Es una instancia representativa de los internos, sus miembros defienden el interés colectivo y no los particulares intereses de un grupo o de personas determinadas. Es democrático porque la postulación, la elección y la gestión del comité se realiza con la participación de todos los internos sin discriminación por razones de raza, color, religión, orientación sexual, condición social o política. El comité actúa en el marco de la ley y de la protección a los derechos de las personas. el mes de noviembre de 2009, cuando uno de los planes de atención estipula que cada seis meses debe realizarse una consulta odontológica general de las personas recluidas de la Cárcel; la prestación del servicio se ha limitado a las urgencias graves que pueden ser remitidas, pero aparte de ello no se realizan otros procedimientos. Al indagar el porqué de esta situación no se encontraron argumentos claros que justificarán estos hechos, pero se logró obtener un acuerdo de atender todos los miércoles a siete internas, mediado que para ello en el momento de la consulta encuentre servicio de agua, de lo contrario no podría llevarse a cabo el acuerdo. No se ha podido verificar si esto se ha cumplido.

Estos graves casos hallados no sólo violan la normatividad internacional relativa a la protección de los derechos de las personas privadas de la libertad expuestos inicialmente en cuanto a la obligación del Estado de garantizar el derecho a la salud, sino que también no cumplen con el artículo 106 de la Ley 65 de 1993 que estipula:

Asistencia médica. Todo interno en un establecimiento de reclusión debe recibir asistencia médica en la forma y condiciones previstas por el reglamento. Se podrá permitir la atención por médicos particulares en casos excepcionales y cuando el establecimiento no esté en capacidad de prestar el servicio (art. 106 de la Ley 65 de 1993).

La regulación para estas situaciones es clara, y se desarrolla a favor de la protección de las condiciones de existencia de los internos, donde tanto la dirección de la Cárcel, como la Administración Distrital no pueden ni deben dilatar las estrategias de solución a estas problemáticas que subyacen a un manejo inequitativo e ineficiente de los recursos, y en especial, a la poca atención prestada a la suerte de los sujetos recluidos. La realidad contradice a lo formal y pone en evidencia la necesidad de generar estrategias de intervención inmediata -y no paliativa- para encontrar una solución estructural que no sólo afecta a los internos, 
sino que también a los guardianes, igualmente victimas de esta situación. En el momento en que fuera cuestionado este tema, estos reconocieron la dificultad que enfrentan, ya que los internos en muchas ocasiones descargan su frustración contra ellos al reconocer en su imaginario un representante de la institución que debe darles soluciones; al igual que ellos han sido afectados por contagio de las enfermedades de los internos lo mismo que a sus familias.

Como estrategia de atención integral al derecho a la salud del cual deben gozar los internos, la Cárcel Distrital ha realizado un convenio de atención con el Hospital La Samaritana, que permite, en los casos de alta complejidad y de extrema urgencia, atención de calidad que preserve la vida de los internos. La calificación obtenida al ser preguntados por este convenio, y por el trámite oportuno con relación al acceso en la atención a la EPS a la cual se encuentran algunos afiliados no es la mejor. Si bien algunos reconocen que no todo es malo, y que en ocasiones la atención en La Samaritana en buena (no tienen queja en cuanto a la atención del hospital, sino la dificultad para acceder al servicio), existen elevados índices de desconocimiento de sus derechos, de los beneficios y de los convenios a los cuales tienen derecho en temas de salud. No se conocen los trámites que deben realizar para obtener estos beneficios, la orientación en estos procesos es escasa, traduciéndose en la práctica en la privación al derecho a la salud.

Este panorama refleja claramente la persistencia de un estado de cosas inconstitucional por parte del Estado en relación a las personas privadas de la libertad, ya que de manera contundente (como se ha citado con anterioridad) la Corte Constitucional, en su Sentencia T-606 de 1998, ha declarado que de la salud del interno debe hacerse cargo el sistema penitenciario con recursos del tesoro público.

De igual manera, un tema que ha generado preocupación y que afectan de manera directa el de- recho de la salud de los internos, hace referencia al trato que reciben las personas que se encuentran infectadas de VIH/SIDA. Es de especial importancia este hecho, pues adicional al estado de vulnerabilidad que por su condición de personas privadas de la libertad poseen los internos, el tratamiento que se le está dando a los casos reportados como positivo frente a la enfermedad o que existe sospecha de poseerla, es el traslado de las personas enfermas a celdas de aislamiento, como protocolo de seguridad. ¿ Es acaso esta condición de enfermo terminal razón valedera para hacer recaer una pena accesoria a los internos que se encuentran en la Cárcel Distrital?

Con base en los instrumentos internacionales referenciados, se observa la flagrante violación en varios casos con relación al trato adecuado y los derechos de las personas privadas de la libertad contagiadas con VIH/SIDA o que posean la sospecha de haberlos contraído. Los hechos expuestos denotan una evidente discriminación al momento de ser separadas de los demás internos por su condición de enfermos, aduciendo la dirección de la cárcel razones de seguridad.

\section{Derecho al debido proceso y derecho de acceso a la justicia}

Uno de los temas que genera mayor sensibilidad entre los internos, hace referencia con el manejo que se le ha venido dando a la política de rebaja de penas, sus cómputos por trabajo realizado y la eficacia con la cual se hacen efectivos para disfrutar de los beneficios procesales. Reconocen los internos la posibilidad que se les ofrece de asistir a talleres y de realizar trabajos que tiene como fin primario ayudar en sus procesos de resocialización, pero de igual forma ayudan al propósito de obtener concesiones en temas como la rebaja de penas. La Ley 65 de 1993 al respecto establece:

Artículo 82. Redención de la pena por trabajo. El juez de ejecución de penas y medidas de seguridad concederá 
la redención de pena por trabajo a los condenados a pena privativa de libertad. A los detenidos y a los condenados se les abonará un día de reclusión por dos días de trabajo. Para estos efectos no se podrán computar más de ocho horas diarias de trabajo.

Los internos expresan en la etapa en la que el juez de ejecución de penas constata la cantidad de horas que han trabajado, el cuello de botella que se presenta, pues a consideración de ellos existe una deficiencia en el proceso de sistematización de la información con respecto al trabajo "intra muros" Esta complejidad se concreta en la demora que algunos internos encuentran cuando han cumplido con su pena e inician el proceso de salida; deben realizar justificaciones constantes de las horas trabajadas para que estas sean validadas, y mientras esto ocurre pueden pasar días o meses de tiempo de más con respecto a la pena inicialmente impuesta.

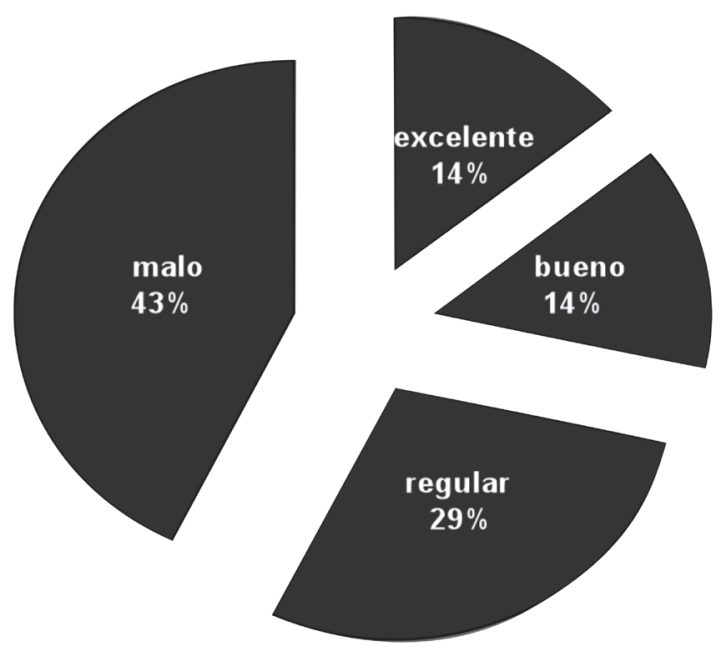

Figura 2. Derecho acceso a la justicia.

En la figura 2 se refleja la percepción de inconformidad que sienten los internos con relación al manejo que se le está dando al computo de las penas, debido a que reconocen que no sólo es un problema de la cárcel, sino que también media de manera fundamental la ambigüedad derivada la ley, ya que deja en manos del juez de ejecución de penas el poder de decidir, según su criterio si las horas certificadas son o no legítimamente obtenidas, y a través de esto obtener su libertad. Hecho que se sustenta en la deficiencia que desde la cárcel se presenta en el manejo de la información; al no ser idóneos los canales de comunicación entre las personas encargadas de tramitar las horas trabajadas dirigidas a los juzgados, se termina en una sin salida que pone a los internos en una situación de justificación probatoria de lo consignado en dichos informes. "Acá uno sabe cuando entra, pero no cuándo sale", es la frase más común de los reclusos, al manifestar su inconformidad con la administración de la cárcel por generar moras para definir su permanencia en el centro penitenciario ${ }^{8}$.

Esta realidad se encuentra en clara contravía con los principios básicos para el tratamiento de los reclusos establecidos por la Asamblea General de Naciones Unidas, los cuales disponen la necesidad de implementar actividades laborales remuneradas y útiles que colaboren en el fin último del sistema penitenciario, la reinserción a la sociedad.

Es necesario, por tal razón, que el cómputo por rebaja de penas tenga incidencia real y efectiva ante las autoridades judiciales de ejecución de la penas, haciendo realidad la posibilidad de descuento punitivo prevista en la ley evitando las demoras en la relación de dichos cómputos.

De otra parte argumentan los internos que si bien es cierto existen talleres y posibilidades de trabajo, estas no son suficientes, demandando una mayor oferta que satisfaga sus necesidades y que los capacite para cuando salgan de la cárcel. Aunado a ello, se critican horarios restringidos, la pobre cobertura y los bajos niveles de capacitación real y efectiva

8 Casa ciudadana de control social. Internos de la cárcel Distrital piden más beneficios para redención de penas. Recuperado el 26 de mayo de 2010 de [http://www.veeduriadistrital.gov.co/es/ noticia.php?uid=0\&leng=es\&det=438\&grupo=280\&leng=es $]$. 
que no permite una resocialización adecuada ni de calidad. Se requiere aclarar la forma en la cual se defines quienes se hacen acreedores al acceso al trabajo en la cárcel, pues si se trata de una opción para todos los internos y al ser beneficiarios, ino se configura en algún grado una circunstancia de discriminación? El desorden -afirman- los reclusos prevalecen en el acceso a las posibilidades de trabajo y de redención, provocando el inconformismo de estos, la desobediencia y la violencia que se acrecentan como opciones de protesta ante esta situación de indignidad.

El derecho a un proceso oportuno y a que se resuelta la situación jurídica de los internos, debe ser una prioridad para la administración de justicia y para las directivas del centro penitenciario, evitando, de esta manera, que estos sean afectados directos por las disfuncionalidades del sistema de justicia, convirtiéndolos en sujeto de especial protección con respecto a las garantías y el disfrute de sus derechos. Recordemos, en este apartado, cómo las Reglas de Brasilia pretenden generar un marco de respeto y exigibilidad de los derechos de las personas en condiciones de vulnerabilidad, para que a través de mecanismos expeditos, eficientes y eficaces se de trámite oportuno y sin dilaciones a los procesos de las PPL; la necesidad de proteger los derechos de los internos comparta el compromiso del sistema judicial de generar cambios estructurales en las disposiciones de atención y trámite de las redenciones, cómputos y libertades de aquellos que han cumplido con su sanción y han logrado su resocialización. Si bien es cierto las citadas reglas no constituyen un tratado, pacto o convenio internacional, su carácter vinculante no puede ser desconocido por las instituciones nacionales en términos de la necesidad de crear estrategias de protección de los derechos de las personas en condiciones de vulnerabilidad; ya la Corte Constitucional ha sostenido:

[...] no han sido aprobados mediante un tratado internacional. Sin embargo, dado que ellos fundamentalmente reflejan y llenan las lagunas de lo establecido en tratados internacionales de derechos humanos y que han recibido una gran aceptación por parte de distintos organismos internacionales de derechos humanos, esta Corporación considera que deben ser tenidos como parámetros para la creación normativa y la interpretación en el campo de la regulación [...] (Sentencia T-419 de 2003,

Mag - ponente, Alfredo Beltrán Sierra).

En otras palabras, el bloque de constitucionalidad asegura que aquellas normas y principios que, sin aparecer formalmente en el articulado del texto constitucional, son utilizados como parámetros del control de constitucionalidad de las leyes, por cuanto han sido normativamente integrados a la Constitución, por diversas vías y por mandato de la propia Constitución, orientando la creación de políticas públicas y la implementación de mecanismos efectivos de protección de derechos humanos y acceso a la justicia de las PPL.

\section{Derecho al trato digno - Derecho a la familia}

Las visitas realizadas a los internos es un tópico que genera preocupación e inconformidad por parte de estos, debido a que la gran mayoría se queja del trato que reciben sus familiares en el momento de ingresar al penal. La manera en que son tratados, recibidos y requisados, resuelta denigrante de su condición de seres humanos, haciéndolos padecer situaciones incómodas y degradantes. Gran parte de las personas entrevistadas señalan el problema de la estigmatización de la familia del interno asegurando que los guardianes han construido un imaginario en el que la condición de condenado por algún delito se traslada a su entorno familiar. De esta manera, el trato -aseguran los internosque reciben sus familiares es el de delincuentes, manifestándose en palabras y expresiones que etiquetan a las personas, lo cual atentan directamente contra su dignidad. Esta situación que los reclusos consideran incorrecta y poco apropiada, ya que el momento de visita esta destinada exclusivamente 
para ellos, que deben compartir con las personas de su entorno familiar que no pueden ver todos los días y con las cuales deben procurar entablar un tipo de relación sostenible en el tiempo y regulada por unos horarios, mediada por los muros de la prisión.

En este punto, es importante tener presentes los principios y buenas prácticas sobre la protección de las personas privadas de libertad en las Américas, enumerados con anterioridad, pues a partir de estas se ratifica la importancia de generar estrategias de control en temas de micro tráfico de estupefacientes, armas o demás artículos que se encuentren expresamente prohibidos por los reglamentos de las cárceles, y que atenten contra el fin último de resocialización y cumplimiento de la pena. Pero, este fin no legitima el uso de cualquier medio para obtenerlo. Las medidas de control deben ser proporcionales y estar a tono con la integridad de la persona, y no atentar contra sus condiciones morales y personales. Los internos expresan al respecto la falta de consideración por parte de quienes ejercen los controles en el penal en el momento del ingreso de la visita y de los artículos y demás cosas que traen consigo, porque la mayoría de los familiares hacen esfuerzos tanto físicos (levantarse temprano para hacer fila) como económicos (compra de determinados artículos) que por consecuencia de los filtros impuestos terminan dejándolos en la calle para poder lograr el ingreso al establecimiento carcelario.

Uno de los elementos fundamentales para lograr una mayoría en estas situaciones es la atención que debe dársele a la calidad del personal que realiza el trabajo de custodia y vigilancia, la cual debe encontrarse en concordancia con las reglas mínimas para el tratamiento de los reclusos aprobada por la Asamblea de Naciones Unidas para la salvaguardar la dignidad de los internos.

Estos funcionarios con relación a sus procesos de formación y capacitación tanto en temas de derechos humanos como en lo propiamente relacionado a su labor técnica, aseguran que los cursos o seminarios que lleguen a tomar se hace por iniciativa propia de cada guardián, pues no existe una política o programa estructurado y periódico que demanda la educación constante en estos temas. Lo dicho por ellos refleja la poca preocupación que se tiene desde la dirección por formar constantemente a su personal para que así el trato hacia los internos y sus familiares sea más idóneo. No sólo es el tema de formación en derechos humanos el que preocupa por su ausencia, sino también el ejercicio y la práctica técnica. Los guardianes aseguran de otra parte, que adolecen de un entrenamiento constante que asegure la respuesta óptima en casos de peligro inminente o de apaciguamiento de un motín.

La regulación de las visitas no permite el pleno disfrute al derecho a la familia, debido a que al ser destinadas para distintos fines de semana al mes, la convivencia real y de calidad que se tiene entre los miembros de la familia es escasa, existiendo demoras en la entrada, situación que reduce el tiempo de permanencia entre los reclusos y sus familiares, hasta la segmentación de los días en los cuales pueden recibir bien a los hijos o bien a sus parejas. Este panorama no ayuda en la consecución del bienestar del interno y tampoco de sus familiares, quienes desempeñan el papel de apoyo y motivación para el cumplimiento de la pena, resocialización y posterior reingreso a la sociedad. EI resultado lógico de todo esto es la división familiar extramuros, la separación de los hijos de su núcleo familiar como ocurre, por ejemplo, en el caso de dos internas que corren el riesgo de perder a sus hijos por las dificultades que enfrentan para acceder y responder a los procesos que se están llevando con relación a la custodia de aquellos por parte del Instituto Colombiano de Bienestar Familiar.

El derecho a la familia, más allá de las limitaciones propias que impone la reclusión penal, debe ser garantizada por el centro penitenciario y la admi- 
nistración de justicia, sin que pueda ser soslayada, so pretexto de la falta de preparación del personal de guardianes, lo mismo que el derecho al debido proceso que tampoco puede ser soslayado cuando se alega la falta de personal suficiente para el traslado a los despachos judiciales, para que los reclusos puedan atender la marcha de los procesos que se adelantan en su contra.

Por otra parte, es fundamental que los internos tengan la certeza de un marco normativo, que su permanencia en el establecimiento carcelario de las reglas y de las sanciones por su transgresión. Las reglas mínimas para el tratamiento de los reclusos en su numeral $35.1^{9}$, a este respecto señalan:

\begin{abstract}
Numeral 35. 1) A su ingreso cada recluso recibirá una información escrita sobre el régimen de los reclusos de la categoría en la cual se le haya incluido, sobre las reglas disciplinarias del establecimiento y los medios autorizados para informarse y formular quejas; y cualquiera otra información necesaria para conocer sus derechos y obligaciones, que le permita su adaptación a la vida del establecimiento (Reglas mínimas para el tratamiento de los reclusos).
\end{abstract}

Al respecto cabe señalar que si bien es cierto no existen un conocimiento suficiente de parte de los reclusos del reglamento y por tal razón pueden argumentar que algunas sanciones impuestos son juzgadas como ilógicas; es necesario, con todo, poner atención a ciertas denuncias acerca de sanciones que se configuran como violatorias de los derechos de las personas privadas de la libertad. Aseguran los reclusos que en el momento de aplicar alguna sanción sus descargos no son escuchados, ya que es la administración de la cárcel manifiesta tener siempre la razón; la sanción en algunas ocasiones no es individual -aplicada tan solo a quien cometió la falta- sino que compromete a todo un patio (sitio de reclusión colectivo).

9 Adoptadas por el Primer Congreso de las Naciones Unidas sobre Prevención del Delito y Tratamiento del Delincuente, celebrado en Ginebra en 1955.
La Corte Constitucional, en la Sentencia T-153 de 1998, reconoce que el problema de las cárceles y de las condiciones de vida dentro de ellas no ocupa un lugar destacado dentro de la agenda política del Estado. A pesar de que desde hace décadas se conoce que la infraestructura carcelaria es inadecuada, que los derechos de los reclusos se vulneran con frecuencia; que los penales no cumplen con su función primordial de resocialización y que los centros carcelarios del país sobrepasan su capacidad ampliamente. Con respecto a esta problemática y es lo que permite la calificación de "estado de cosas inconstitucional" no se observa una actitud diligente de los organismos políticos del Estado con miras a poner remedio a estas situaciones, reconociendo la urgencia de destinar el presupuesto necesario para que la infraestructura carcelaria permite su centros donde los derechos fundamentales tengan plena vigencia.

\section{Derechos sexuales y reproductivos}

Las personas privadas de la libertad, presentan restricciones en algunos de sus derechos por razón de la falta cometida y encontrarse en proceso de resocialización. Ello los convierte en una población en condiciones de vulnerabilidad, con respecto a la cual el Estado debe hacerse responsable por asegurar -con las limitaciones propias de su situación- una vida digna y el disfrute pleno de sus derechos. Retomando los Principios Básicos para el Tratamiento de los Reclusos aprobados por la Asamblea General de Naciones Unidas, se recuerda que con excepción de las limitaciones que sean necesarias por el hecho de encarcelamiento, las PPL tendrán garantizados el resto de sus derechos.

En otras palabras, la pena impuesta por el operador de justicia no puede traducirse en una excusa propicia para privar a los internos que se encuentran en los centros de reclusión de una serie de derechos por conveniencia o preferencias ideológicas del personal de guardia y vigilancia o del personal administrativo de los centros penitenciarios. 
Colombia posee un desafortunado índice de discriminación en materia de derechos sexuales y reproductivos, en especial en términos de respeto frente a la autodeterminación y orientación sexual de las personas. Dicha discriminación se hace evidente con mayor fuerza en los centros de reclusión del país, pues el control y la disciplina ejercida por un orden vertical patriarcal, hace que en los procesos de resocialización se pretenda también influir en la vida privada de las personas y provean a una normalización de las conductas sexuales de las personas. (...) en el espacio de confluencia del poder disciplinario con el bíopoder, se encuentra el sexo, lo que proporciona a la sexualidad y a su historia una privilegiada posición estratégica: el sexo es, a su tiempo, acceso a la vida del cuerpo y a la vida de la especie. Es utilizado como matriz de las disciplinas y principio de las regulaciones (Foucault, 2005, p. XXVII).

Las personas LGBT que se encuentran recluidas en establecimientos carcelarios sufren condiciones de hacinamiento y son víctimas de la violencia. La posibilidad de ejercer sus derechos básicos es muy precaria. Este estado de vulnerabilidad es compartido con la totalidad de la población carcelaria: Ios imaginarios de la prisión están marcados por el prejuicio y las lógicas de dominación machistas y homofóbicas. A pesar de las normas nacionales e internacionales, y de la jurisprudencia sobre la discriminación y el estado de vulnerabilidad que afecta las personas LGBT recluidas en las cárceles, las autoridades penitenciarias no han tomado medidas que garanticen plenamente sus derechos (Colombia Diversa, 2006-2007, p. 113).

Las mujeres lesbianas y bisexuales en las cárceles sufren el rechazo y la discriminación, no sólo del personal de guardia sino también de sus compañeras heterosexuales. La guardia penitenciaria tiene comportamientos discriminatorios y arbitrarios que entre otras formas se manifiestan en agresiones verbales. La violencia verbal de este personal, que es la autoridad legítimamente y responsable de proteger los derechos de las reclusas, es muy preocupante, y lo es en más de un sentido: sus agentes no sólo incumplen su deber de garantes del Estado, sino que además son partícipes directos de las violaciones de los derechos humanos $y$, como si fuera poco, incitan a otras internas a ejercer la violencia física (Colombia Diversa, 20062007, p. 144).

La Cárcel Distrital no posee un protocolo formalizado con relación a la atención y a la salvaguarda de los derechos sexuales y reproductivos de las parejas del mismo sexo, situación que alimenta la discrecionalidad con la que el cuerpo de guardia y custodia maneja los potenciales casos que se puedan presentar. En la eventualidad que una pareja del mismo sexo desee ingresar al penal de visita, el reglamento no procura mecanismos de protección y no discriminación de las orientaciones sexuales de las personas, colocando en riesgo de estigmatización y violencia por parte del personal de guardia a aquellos visitantes. La Corte Constitucional en la Sentencia T-499/03, referida con anterioridad, anota que los centros carcelarios no pueden escatimar esfuerzos con miras a garantizar el ejercicio de la sexualidad en condiciones de libertad, intimidad e igualdad, salvaguardando la dignidad de las personas privadas de la libertad, sin desconocer las condiciones específicas de cada establecimiento.

\section{CONCLUSIONES}

El recorrido normativo nacional e internacional, junto con las condiciones de los internos expuestas a lo largo del artículo, demuestran que aún se encuentra lejos el respeto pleno y la garantía de los derechos de las personas privadas de la libertad en la Cárcel Distrital.

Los hechos descritos, producto de las visitas realizadas, no deben ser tomados como realidades coyunturales, como una visita en "mala hora" en la que se presentaron problemas que se tienen 
controlados. Si algo se ha visto, es que la violencia generada hacia los internos es estructural desde las disposiciones, los canales de comunicación, la prestación de los servicios y los imaginarios construidos de las personas recluidas que atentan de manera flagrante con su integridad personal y menoscaban sus procesos de resocialización.

En el plano internacional la suerte de las personas privadas de la libertad es una preocupación relevante en temas de protección y garantías de sus derechos. Lo analizado en este trabajo permite observar cómo la realidad está en contravía de las disposiciones de Naciones Unidas y de la Convención Interamericana de Derechos Humanos de la cual Colombia es signataria.

De igual manera ocurre en el plano nacional. La Corte Constitucional ha elaborado una jurisprudencia de factura jurídica, teórica y conceptual para la defensa y el restablecimiento de los derechos de los internos en Colombia. Desafortunadamente estas disposiciones judiciales no han sido acatadas plenamente por las directivas de la cárcel Distrital, y de otras cárceles del país-. Las cuales deberían atenderlas sin más dilación a fin de superar el "Estado de corte inconstitucional" que afecta a los establecimientos carcelarios del país. "El Efecto Gulliver" tiene en este tema una de sus más claras y concretas verificaciones. Una Corte con una extraordinaria jurisprudencia con un estado de instituciones mezquinas, enanas y avaras en materia de realización de los derechos fundamentales. La Corte Constitucional de otra parte debería reasumir su competencia para verificar el cumplimiento eficaz y eficiente de sus fallos.

\section{REFERENCIAS}

Ariza, R. (2007). La justicia restaurativa para adolescentes en Colombia. Bogotá: Fundación Civis.

Carvajal, J. (2008). La seguridad dentro del estado de garantías. Bogotá: Instituto Latinoamericano de Servicios Legales Alternativos.
Fajardo, L. (2005, julio-diciembre) La protección de IOs DESC en el Sistema Interamericano de Derechos Humanos. En: IUSTA, 23.

Fajardo, L. \& García L. (2007, enero). Justicia para todos. El reto del Programa Nacional de Casas de Justicia. En: IUSTA, 26. Bogotá.

Fajardo, L. (Coord.) \& García, L. (2009). Utopía y Jurisprudencia Constitucional. El enfoque progresista de la Corte Constitucional Colombiana. Bogotá: Universidad Santo Tomás.

Fajardo, L. (Coord.); García, L \& Abondano, D. (2007). Los invisibles y la lucha por el derecho en Colombia. Bogotá: Universidad Santo Tomás.

Colombia Diversa. (2006 - 2007). Derechos humanos de lesbianas, gays, bisexuales y transgeneristas en Colombia.

Corte Interamericana de Derechos Humanos. (2010). Documentos básicos en materia de derechos humanos en el Sistema Interamericano: Actualizado a febrero de 2010 San José, C.R

Foucault, M. (2000). Defender la sociedad. México: Fondo de Cultura Económica.

Foucault, M. (2001). Vigilar y castigar. Nacimiento de la prisión. México: Siglo Veintiuno Editores.

Foucault, M. (2005). Historia de la sexualidad. La voluntad de saber. México: Siglo XXI.

Goffman, E. (1998). Estigma. Argentina: Amorrortu Editores.

Herreño, L. (2008). ¿Todo o nada? Principio de integralidad y derechos sociales. Bogotá: ILSA.

Programa de Naciones Unidas para el Desarrollo - PNUD (2006). Diseño de un modelo práctico de ejercicio de los derechos humanos en la Cárcel Distrital. 
Asamblea General de Naciones Unidas. Conjunto de principios dirigidos a la protección de todas las personas sometidas a cualquier forma de detención o prisión. Resolución 43/173 de 9 de diciembre de 1988.

Los principios básicos para el tratamiento de los reclusos. Resolución 41/111 de 14 de diciembre de 1990.

Primer Congreso sobre Prevención del Delito y Tratamiento del Delincuente (1955). Ginebra. Aprobadas por el Consejo Económico y Social, resoluciones 663C (XXIV) de 31 de julio de 1957 y 2076 (LXII) de 13 de mayo de 1977, las Reglas Mínimas para el Tratamiento de los Reclusos

Reglas de Brasilia sobre acceso a la justicia de las personas en condición de vulnerabilidad, aprobada en 2008 en la XIV Cumbre Judicial Iberoamericana.

Comisión Interamericana de Derechos Humanos. Principios y buenas prácticas sobre la protección de las personas privadas de la libertad en las Américas (OEA/Ser/L/V/II.131 doc. 26)

Corte Interamericana de Derechos Humanos. (2005). Sentencia del Caso Fermín Ramírez vs Guatemala.
Directrices sobre el VIH/SIDA y los derechos humanos, aprobada en la Segunda Consulta Internacional celebrada en Ginebra en 1996.

Directrices de la OMS sobre la infección por el VIH y el SIDA en las cárceles publicadas en 1993.

Periódico El Espectador. Distrital, la cárcel modelo. Recuperado el 26 de mayo de 2010 de [http://static. elespectador.com/infografias/carcel/index.html].

Sentencia T-153 de 1998, M.P. Eduardo Cifuentes.

Sentencia T-606 de 1998, M.P. José Gregorio Hernández.

Sentencia T-499 de 2003, M.P. Álvaro Tafur Galvis.

El Procurador General de la Nación alerta frente al grado de realización del derecho a la salud de las personas privadas de libertad (2004, septiembre). Bogotá.

Defensoría del Pueblo. (2009). XVI Informe del Defensor del Pueblo al Congreso de la República. 